\title{
VAKDIDAKTIEK AS NOODSAAKLIKHEID IN VERPLEEGONDERRIG EN -OPLEIDING
}

MEV A W BEEKMAN Junior Lektrise, R.A.U. (Verpleegonderwys) Hons. B.Soc. Sc. (Verpleegkunde) (U.O.V.S.) M.Cur (Verpleegonderrig)(R.A.U.)

\section{MEJ A A BASSON Lektrise, R.A.U. (Gemeenskapsverpleegkunde) B.Cur (Ed et Adm) (R.A.U.) M.Cur (Verpleegonderrig)(R.A.U.) VAKDIDAKTIESE KOMPONENTE}

\section{A W BEEKMAN}

\section{SUMMARY}

Subject didactics, part of the discipline Education, is receiving renewed attention. It involves the study of how the educational process concerning a specific subject can be optimalised. Subject didactics in a nursing subject will bring together all applicable facets of didactics, the practical organisation of the teaching situation and the particular nursing content.

A number of universities are now offering subject didactics as a separate subject in the curriculum for students in nursing education. An example is given of how subject didactics in community nursing is offered at this level.

\section{INLEIDING EN ORIËNTERING}

Vakdidaktiek as deeldissipline van die Opvoedkunde is nie 'n nuwe tendens of stroming nie. Volgens Maarschalk het die eerste pogings gewissel tussen twee uiterstes, naamlik vakkennis aan die een kant en die didaktiese aspekte van die vakdidaktiek (destyds bekend as metodiek) aan die ander kant Hierdie twee komponente is oorbeklemtoon met die gedagte dat die res, naamlik die didaktiese van vakkennis (die kán) en die vertaling en interpretering van die vakinhoud, vanself tot hul reg sal kom (Maarschalk, p.2).

Op die oomblik is daar egter 'n hernude besinning en daadwerklike projekte ten opsigte van vakdidaktiek, aldus Maarschalk (p.2).

Die terrein van die vakdidaktiek word breedweg aangedui as daardie gebeure (didakties en onderwyskundig) wat gerig is op optimalisering van die onderwysleergebeure. Vakdidaktiek is in wese dus die ver- besondering van 'n spesifieke vak Hierdie verbesondering het sy aanloop vanuit die Didaktiese Opvoedkunde en die Onderwyskunde waar dit van die algemene en omvattende vakdidaktiek af beweeg het tot die besondere vakdidaktiek vir die verskillende vakke. Die segswaarde en kenmerk van die vakdidaktieke lê opgesluit in die verbesondering en dit sluit dus ook aangeleenthede in soos onderwysdoelstellings. lesdoelwitverwesenliking, leerstofordening, didaktiese werksvorme en evalueringspraktyke (Maarschalk, p.2). Van Dyk en Van der Stoep sê van die terrein van die vakdidaktiek dat 'n mens telkens te make het met 'n besondere vak, 'n besondere klas, 'n voorafbepaalde en besondere tydsduur en 'n besondere doelstelling (Van Dyk et al, p.25)

Wanneer 'n mens egter oor die vakdidaktiek besin kan jy nie in isolasie werk nie. Jy het te doen met die probleem van onlosmaaklike ineengestrengeldheid van die verskillende deeldissiplines van die Op- voedkunde asook met die besondere vak waaroor jy besin

Vakdidaktiek op sigself, is nie "n nuwe terrein in die verpleegonderwys nie. Die beginsels van didaktiek is tot dusver in die leerplan van Verpleegonderwys opgeneem. Met die hernude belangstelling en besinning oor die vakdidaktiek het daar egter ook in die Verpleegonderwys in duidelike behoefte ontstaan om van die meer algemene vakdidaktiek na besondere vakdidaktiek in verskillende vakke te beweeg, te wete Algemene Verpleegkunde. Psigiatriese Verpleegkunde. Verloskundige Verpleegkunde en Gemeenskapsverpleegkunde. Didaktiek in hierdie vier vakke word reeds van vanjaar af in sommige universiteite as ' $n$ aparte vak aangebied.

DIE FUNDERING VAN VAKDIDAKTIEK IN DIE VERPLEEGONDERWYS

Daar dit " $n$ relatief nuwe terrein is sal daar gepoog word om 'n bena- 
dering tot vakdidaktiek in Verpleegonderwys uit te lig. Hierdie benadering is gerig op die basiese dissiplines wat betrokke is, naamlik, die Didaktiese Opvoedkunde. Onderwyskunde en die Verpleegkunde.

\section{Die didaktiese}

Didaktiek is soos Van der Stoep aandui, afgelei van die Griekse didaskein, wat onderrig gee of om te leer beteken. Hierdie Griekse grondwoord is ook die grondnoemer van begrippe soos didaskalos (onderwyser), didaskalia (onderwysberoep), didaché (die inhoud wat onderrig moet word) en didaktikos (persoon wat hom besig hou met onderrig). Hieruit word afgelei dat die didaktiek die versamelnaam vir komponente van die teorie oor onderwys is. Volgens Van der Stoep kan die didaktiek in die breë beskryf word as 'n teorie oor wat die begrip onderwys behels: watter voorwaardes vir die goeie verloop van die onderwys geld; watter algemene beginsels in ag geneem moet word; watter vorme die onderwys kan aanneem; watter metodes van onderwys ter sprake kan kom; watter verband daar tussen leer en onderrig bestaan; wat leerstof is: die wyse waarop dit georden kan word: watter herstellende en korrigerende optredes bestaan (Van der Stoep, p.18-19).

Hierdie fasette is van wesentlike belang in die verpleegonderwys. Sodra iemand iets sinvol aan 'n student verduidelik, ontstaan 'n didaktiese situasie waar daar moontlikheid is vir leer. Of die student tot lering geaktiveer word hang egter daarvan af of bogenoemde fasette tot hul reg kom (Van Vuuren: p.354). Die fasette word vervolgens beskryf.

\section{Die student}

Die verpleegopvoeder, as didaktikus, moet die volgende weet: Wie en wat is die student (as mens, as leerder, as lid van die gesondheidspan)? Wat is die kenmerke van die volwasse leerder? Wat is die kriteria waarvolgens die leerstof geselekteer en gerangskik word? Om so onderrig te gee, moet die verpleegopvoeder vanuit die didaktiese oog- punt kennis neem van die teorieë oor leer, asook van ander psigologiese, sosiologiese en antropologiese gegewens wat bevorderend of belemmerend vir die leersukses is (Van Vuuren, p.355).

\section{Die verpleegopvoeder (dosent)}

'n Uiters belangrike aspek is dié van persoonlikheid. Die dosent moet nie net 'n koue-kliniese bereidwilligheid toon van 'n kom-na-my-toe-asjulle-probleme-het nie. Sy moet 'n houding hê van ware toegeneentheid, 'n hartlikheid wat vertroue inboesem en waarin daar ' $n$ intiemheid en openhartigheid opgesluit lê. So 'n persoonlikheid gaan hand aan hand met iemand wat haar werk geniet en 'n positiewe houding jeens haar vak en werk uitstraal.

Ook is dit belangrik dat sy kundig sal wees. Sy moet nie net vakkundigheid in die opsig van kennis oor die vakterrein hê nie, maar sy moet ook as inisieerder van die didaktiese gebeure so kundig wees dat sy alle fasette van ontwikkeling en groei vir die student sal ontsluit.

\section{Die onderrigdoel}

Die verpleegopvoeder moet haar deeglik van die onderrigdoel vergewis. Leerstof word immers met 'n spesifieke doel in die leerplan ingesluit. Behalwe die spesifieke doelwitte wat met elke onderrigsessie bereik moet word, moet alle onderrig ook gerig word op die uiteindelike doel, naamlik om 'n studentverpleegkundige te onderrig en op te lei tot ' $n$ volwaardige professioneel-volwasse verpleegkundige wat persoongesentreerde verpleegsorg aan die individu, gesin en gemeenskap op 'n voorkomende en bevorderende, kuratiewe en rehabilitatiewe vlak oor die hele lewenspektrum kan gee.

\section{Leerstof en kurrikulum}

Die dosent aktiveer die student deur die leerstof. Leerstof moet relevant, aanvaarbaar, toepaslik en realisties wees. Leerstof moet as ' $t$ ware die student uitnooi, haar aanspreek. Dit is ook die taak van die dosent om die student tot 'n positiewe ingesteldheid teenoor die leerstof te lei sodat sy die doel van die verwerking van die besondere leerstof kan bereik. Hierdie oordrag van kennisinhoude en vaardighede van dosent na student geskied doelbewus, planmatig en doelstrewend. Daarom word bepaalde leerstof geselekteer, gegradeer en gerangskik en dit word dan 'n kurrikulum genoem, aldus Van Vuuren (p.358). Laasgenoemde stelling is oorvereenvoudig - kurrikulumontwikkeling sluit wel bogenoemde in maar is ' $n$ meer dinamiese komplekse siklus vanaf 'n situasieanalise, doelformulering, seleksie van inhoud en metodes, tot evaluering.

\section{Onderrigmetode}

Die didaktiek bestudeer ook die onderrigmetodes en bepaal hoe onderrig gegee moet word om doeltreffend te wees. Dit sluit in projekmetodes, groepmetodes, probleemstellingsmetodes, die lesingmetode en vele ander.

\section{Onderrigmiddele}

Die didaktiek maak 'n studie van watter hulpmiddels 'n dosent kan inskakel by haar metode van onderrig om die student die direkste en effektiefste op te roep om met aandag te leer en te begryp wat sy leer.

\section{Evaluering}

Dit is meer as net meting. Dit is 'n bepaling van hoe suksesvol die onderrig was en, indien nie, waar die leemtes is.

\section{Remediëring}

Dit is die regstelling van leemtes in die onderrig wat gegee is.

Vir die dosent kan die beginsels van genoemde aspekte nie oorskat word nie. Nie net vorm dit 'n bousteen in haar opleiding as dosent nie, maar vorm dit ook die basis waarop sy haar onderrig gaan bou. Vanuit so ' $n$ verwysingsraamwerk is dit veel makliker om die grondbeginsels van die onderrigproses te begryp en na waarde te skat.

\section{Die onderwyskundige}

Die Onderwyskunde is volgens De Corte nog 'n relatief jong dissipline waarvan die bydrae tot vernuwing van die onderwys reeds groot verwagtinge gaande gemaak het. Die 
Onderwyskunde ondersoek die onderwyspraktyk met die oog op optimalisering van die praktyk (Kruger p.1)

Vir die doel van die vakdidaktikus is die belangrikste terrein van die Onderwyskunde daardie gedeelte wat handel oor die organisasie van konkrete onderwyssituasies binne klas- of leergroepverband. Die vakdidaktikus is dus afgespits op die bestudering en optimalisering van die onderwysleerhandelinge (Studiehandleiding p.3).

Die Onderwyskunde is as vakgebied ontwerp om funksionele integrasie van teorie en praktyk optimaal te laat plaasvind. Dit is in hierdie vak nie net van belang dat studente se didaktiese vaardighede optimaliseer word nie, maar ook dat die studente die geleentheid sal kry vir implementering van didaktiese beginsels (Kruger p.48-60).

Benewens 'n teoretiese grondslag wat handel oor aspekte soos kurrikulum ontwerp, lesstruktuur, lesa anbieding, lesaanbiedingsvaar dighede, leermilieu en evaluering is die praktiese komponent van hierdie vak van deurslaggewende belang. Hierdie komponent maak ongeveer die helfte van die kursus in Onderwyskunde uit en bestaan uit die volgende

- Instituutpraktikum Dit is onderwysoefening in laboratorium omstandighede en bestaan hoofsaaklik uit gesimuleerde en geinduseerde of eksperimentele vorme van didaktiese situasies. Video- en klankopnames word opgeneem en onderwyskundig analiseer en evalueer.

- Kollegepraktikum Behalwe die voordeel van die werklikheid, bied die kollege sekere ervarings wat nie in instituutpraktikum moontlik is nie. Voorbeelde hiervan is dat die student leer om verantwoordelikheid te aanvaar vir die gehalte van die leereffek, kontrole, dissipline, selfhandhawing, administratiewe funksies en vele meer (vgl. Kruger p.48-60)

Hoewel Onderwyskunde, soos genoem, gerig is op optimalisering van onderrigleergebeure, maak dit deel uit van die totaie onderwysopleiding en dien dit as knooppunt tussen byvoorbeeld Verpleegkunde, Verpleegonderwys en die Didaktiese Opvoedkunde

\section{Die verpleegkundige}

\section{Verpleegkundige verantwoord- baarheid}

In die onderrig van die Verpleegkunde, is dit essensieel dat die grondslae, naamlik die antropologiese, sosio-agogiese, aksiologiese, tegnologiese en professionele dimensies, die basis van alle gebeure in die verpleegonderwys sal vorm. Alle aspekte van verpleegonderwys moet byvoorbeeld teen die agtergrond van die verplegingsfilosofie gesien word. So ook sluit alle aspekte van verpleegonderwys die begeleidingsgebeure in.

Om so verantwoordbaar te kan optree, beteken dit dat die verpleegopvoeder, " $n$ ondubbelsinnige en dieptekennis sal hê van eerstens Wat is verpleging? en tweedens van Wat is die doel van verpleegonderwys? Derdens moet sy oor vakspesialisering beskik. Basiese kennis van die vak waarin sy doseer is nie genoeg nie - daarom moet dosente by uitstek in voortgesette studie betrokke wees.

Ander fundamentele beginsels wat essensieel is in verpleegonderwys, is die korrelasie tussen teorie en prakıyk. Elke onderrigprogram moet voorsiening maak vir hierdie aspek. Wanneer "n student byvoorbeeld verpleegfunksies in die praktiese situasie uitvoer sonder die nodige teoretiese basis, is dit streng gesproke nie praktikum nie.
Hoewel daar tans praktiese probleme is, sal hierdie saak hopelik in die toekomstige nuwe bedeling vir verpleegonderwys grotendeels uitgeskakel word deur die teenwoordigheid van meer kliniese onderrigpersoneel in die praktiese situasie.

Breër beginsels, soos die behoefte aan en aanvraag van die gemeenskap na gesondheidsorg. asook die nasionale gesondheidsbeleid oor diensverskaffing en die rol van die verpleegkundige maak ook deel uit van die doel en filosofie waarvolgens verpleegonderwysgebeure beplan en uitgevoer word Die dosent moet dus kennis hê van verpleging as professie en van verpleegonderwys in die breë.

Die fundering van die vakdidaktiek kan samevattend skematies voorgestel word soos uitgebeeld in figuur 1.

\section{PRAKTYKWORDING VAN VAKDIDAKTIEK}

Wanneer die verpleegopvoeder vakdidakties te werk wil gaan. kan sy uit verskeie onderrigmodelle kies soos byvoorbeeld die bildungteoretiese model, leerteoretiese model. kurrikulummodel, ensovoorts.

'n Model wat maklik verstaanbaar en logies is, is byvoorbeeld die leerteoretiese model wat soos in figuur 2 deur Bouman Academie skematies voorgestel word (vgl Breuk \& Brongers, pp. 21-23)

\section{Doelstelling}

Om die vraag: Wat wil ek bereik? te beantwoord, moet daar doelgerigte beplanning wees. Eerstens moet daar doelstellings wees met 'n breë riglyn wat op die uiteindelike uit-

\section{FIGUUR 1: SKEMATIESE VOORSTELLING VAN DIE FUNDERING VAN DIE VAKDIDAKTIEK}

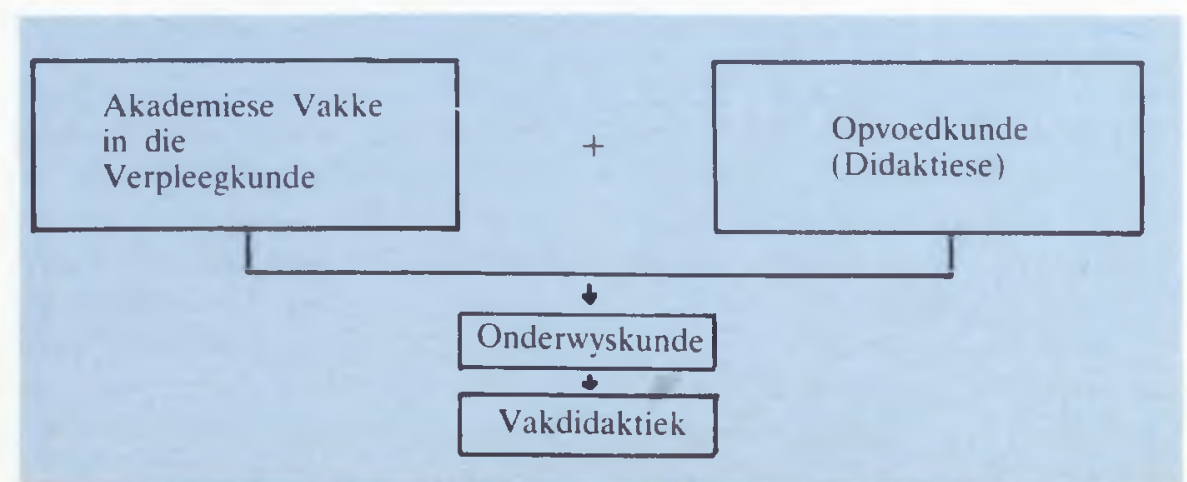




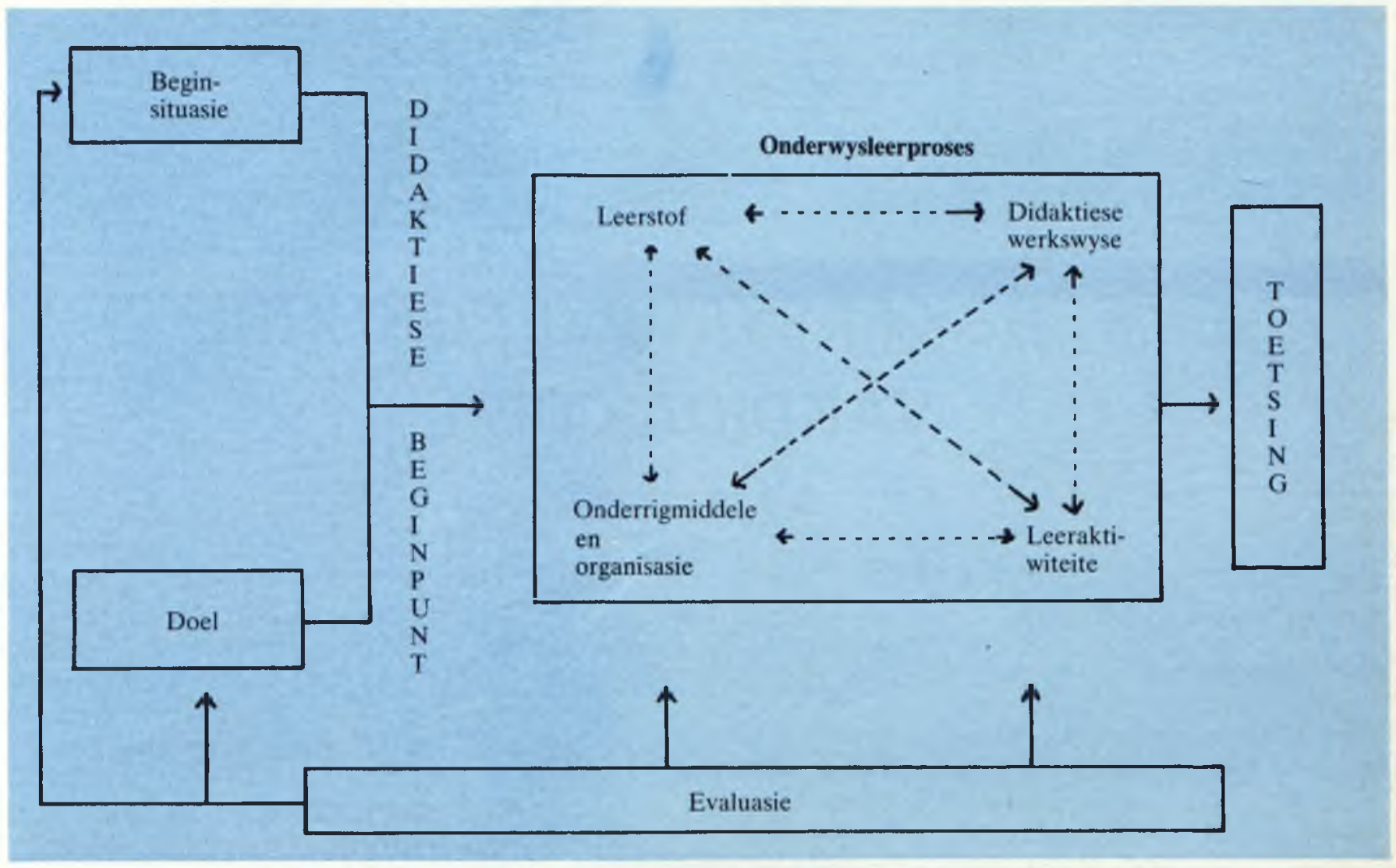

koms gerig is. Tweedens moet daar spesifieke doelwitte wees wat 'n juiste stelling is waarin die gewenste prestasie of gedrag wat na die onderrigleergebeure van die studente verwag word, beskryf is.

\section{Beginsituasie}

Dit sluit in 'n situasieanalise van al die betrokke fasette, naamlik

- student agtergrond, ervaring. kennis, vaardigheid, vermoëns, belangstellings

- dosent didaktiese vaardigheid. houding, ondervinding, ensovoorts

- studentegroep groepsgevoel en houding teenoor dosent en vakgebied

- situasie tipe opleiding (soos blokmetode), geleenthede vir praktikum, tye beskikbaar vir praktikum en studie, hulpbronne, biblioteekfasiliteite, ensovoorts.

\section{Didaktiese beginpunt}

Op grond van die situasieanalise en die doelstellings bepaal die dosent hoe sy lestemas, 'n lesreeks of 'n enkel lesing sal aanbied.

\section{Onderwysleerproses}

Dit is die samestelling van maatreëls wat gerig is op die oorbrugging van die beginsituasie tot die realisering van gestelde doelstellings. Die volgende komponente kan onderskei word.

\section{Leerstof}

Dit dui op die kognitiewe, affektiewe en psigomotoriese inligting wat nodig is om die leerdoel te bereik. Die dosent moet sorg dat die leerstof op 'n tydstip aangebied word wanneer die studente gereed is om die leerstof te verwerk.

\section{Didaktiese werksvorme}

Die aanbieding van die leerstof moet tot leerervaring by die student lei. Hierdie ervaring is reeds in die doelstelling geformuleer, byvoorbeeld

- oefening (hartmassering op 'n model - kan tydens 'n demonstrasie geskied)

- opdrag (skets van die nier in dt , opstel van die verpleegsorgplan)

\section{Leeraktiwiteite}

Omdat studente individueel verskil, leer hulle ook op verskillende wyses. Daarom is dit belangrik dat die dosent in staat sal wees om verskillende leerwyses te implementeer, soos: oefening, probeer en tref, herhaling, nabootsing, eksperimentering en so meer.

\section{Hulpmiddels en Organisasie}

Hulpmiddels is byvoorbeeld modelle, skyfies, rolprente, en transparante.

Organisasie het te doen met die rangskikking en hantering van die groep studente en dit sluit die volgende in

- Word onderrig klassikaal, in groepe of individueel gegee?

- Word ' $n$ uniforme of gedifferensieerde leersituasie beplan?

- Gaan studente betrek word? Wanneer en hoe?

- Is daar vir beplande begeleiding voorsien?

\section{Evaluasie}

Dit kan deurlopend en terminaal geskied. Die dosent beoordeel in hoe 'n mate die studente die onderrigdoelwit bereik het en tweedens hoe die didaktiese handelinge verloop het.

Die toepassingswaarde van vak- 
didaktiese aspekte in 'n model soos bogenoemde lê opgesluit in die individuele dosente se inisiatief, kreatiwiteit, geesdrif en werklike strewe na optimalisering van onderrig. Die sukses hang af van daardie mate waartoe sy bereid is om haar vak te ontleed en op eksperimentele basis uit te toets vir onderrigeffektiwiteit.

BIBLIOGRAFIE

Breuk. J W: Brongers C A H Didactiek van de Lichamelijke opvoeding. No. 34 van de geschriften van het jan Luiting fonds. Koninklijke Nederlandse Vereniging van Leraren en Onderwijzers in de Lichamelijke Opvoeding. 1979 3e uit.

2. Kruger. R A red e.a. Onderwyskunde en Onderwisersopleiding. (Opvoedkundige publikasie-recks. R.A.U. ir. 2). Butterworth Durban 1981

. Maarschalk J Verantwoorde Vakdidaktiek. R.A.U Johannesburg 1982

4. Van der Stoep F Inleiding tot die didaktiese pedagogiek Academica Pretoria 1976

Van Dyk C J: Van der Stuep F Inloiding tor die Vakdi daktiek Perskor Johannesburg 1977

6. Van Vuuren, J C G red Oriënsering in die pedagogiek Unisa Pretoria 1976

7. Studiehandleiding - Onderwyskunde D. Randse Afrikaanse Universiteit

\section{GEMEENSKAPSVERPLEEGKUNDE - VAKDIDAKTIEK}

\section{A A BASSON}

\section{DIE AARD VAN GEMEEN- SKAPSVERPLEEGKUNDE}

Die eerste openbare gesondheidsverpleegster wat in die stad werksaam was, was hoofsaaklik gemoeid met gesondheidsvoorligting aan moeders oor die versorging van gesonde babas, immuniseringsdienste, voorgeboortelike versorging, aspekte van baba- en kleuterwelsyn, tuberkulose, veneriese siektes en skoolgesondheidsdienste. Met verloop van tyd het psigiatriese nasorgdienste, genetiese raadgewing, gesinsbeplanning en geriatriese versorging bygekom. (Searle: p.2)

Steeds hoër eise word vandag gestel aan die gesondheidswerker ten opsigte van die Suid-Afrikaanse bevolking.

Die waarde en die regte van die individu word al hoe sterker beklemtoon. Gevolglik word dit 'n eis van ons tyd en geregverdigde verwagting dat die kwaliteit van lewe sodanig moet wees dat dit met vreugde aanvaar kan word. Dit is egter nie alleen die individu wat hoë verwagtinge het nie. maar die mediese wetenskap en snel ontwikkelende tegnologie wat ook eise stel vir 'n meer gesofistikeerde diens met gepaardgaande etiesnormatiewe vraagstukke wat daaruit voortspruit (Munnik: p.3).

Die opleiding van die gemeenskapsverpleegkundige moet dus van so ' $n$ aard wees dat sy toegerus is om sinvol te kan praktiseer. Afgesien daarvan dat die onderwys-student die kursus in Gemeenskapsverpleegkunde volg, moet sy ook die verbesondering van Gemeenskapsverpleegkunde bemeester om dit sodoende te kan onderrig.

\section{DOEL VAN DIE KURSUS}

As die student Gemeenskapsverpleegkundige Vakdidaktiek as vak kies, is sy reeds in 'n mate vertroud met Gemeenskapsverpleegkunde en Opvoedkunde. Die hoofdoel van die kursus is om die twee strukture bymekaar te bring en ineen te laat smelt in die klaskamersituasie of praktiese onderrigsituasie, soos mens dit aantref by die onderrig van Gemeenskapsverpleegkunde. So ontwikkel die student 'n eie verantwoordbare siening en metode van Gemeenskapsverpleegkunde - onderwys, wat nie staties moet bly wanneer die student eendag in die praktyk staan nie, maar voortdurend aangepas en herevalueer moet word (Maarschalk: p.8).

Daar word van die student verwag om nie net insig te verwerf in die onderwysleersituasie nie. maar ook om 'n sekere bedrewenheid en vaardigheid ten opsigte van les-optrede te ontwikkel. Hierdie insig en vaardigheid vloei onder meer voort uit haar doelgerigte waarneming van lesse (haar eie en dié van ander) en die werklike opdoen van onderwyservaring (instituutpraktikum en kollegepraktikum). Die student ontdek haar eie unieke onderwysstyl en verbeter op 'n sinvolle en verantwoordbare wyse binne die raamwerk van Gemeenskapsverpleegkunde voordat sy die vak self aanbied. Sy besin dus indringend oor haar onderwysstyl aan die hand van die kernlesings en besprekings in die groepklasse en by die proeflesings wat sy in $\mathrm{Ge}$ meenskapsverpleegkunde gee.

\section{METODE WAT IN DIE KURSUS GEVOLG WORD}

Die kursus bestaan uit twee dele.

\section{Teoretiese deel}

In die teoretiese deel vind kurrikulering van die hele Gemeenskapsverpleegkunde-sillabus plaas.

'n Situasieanalise word gemaak van die hele leerplan, waartydens die student die sillabus analiseer tot verskillende modules. Doelstellings en doelwitte word opgestel sodat die leerder weet wat van haar verwag word.

Die leerinhoud word geselekteer en relevante literatuur word voorgeskryf waartydens die student sinvolle leergeleenthede vir haar leerders skep. Doelgerigte leerervaring word beplan sodat dit evalueer kan word tydens begeleiding in die praktyk of deur similasie (Kruger: p.8).

\section{Praktiese Deel}

Tydens die praktiese deel word praktiese ondervinding by die onderrig van studente in Gemeenskapsverpleegkunde opgedoen. Die student bied lesse aan mede-studente en/of simulasielesse aan. asook op videoband om haarself te evalueer. Kommunikasievaardighede word aangeleer om individue 
en groepe tydens onderrig en begeleidingspraktikum te hanteer. Werkskemas word opgestel, vraestelle word opgestel en nagesien, transparante, hulpmiddels, plakkate, modelle en so meer word gemaak. Die gedagte is dat die student 'n voorraad onderwysmateriaal opbou vir wanneer sy ná die kursus Gemeenskapsverpleegkunde aanbied.

Sy het dan reeds haar studiehandleiding wat sy tydens die kursus saamgestel het asook haar media en is dus gereed om die doseerveld te betree.

\section{SLOTSOM}

Die noodsaaklikheid van vakdidak- tiek in die opleiding van dosente kan nie oorbeklemtoon word nie. Nie alleen word doseereffektiwiteit in 'n spesifieke vak verhoog nie, maar is die moontlikheid ook daar om studente beter voor te berei as verpleegkundiges op die spesifieke vakgebied.

Soos uitgespel beteken dit egter dat diegene wat gemoeid is met die opleiding van dosente weer eens 'n deeglike studie sal moet maak van die onderliggende didaktiese, onderwyskundige en verpleegkundige aspekte en daarvolgens in model of verskillende modelle implementeer waarvolgens didaktiek ten opsigte van die onderskeie vakke naamlik: Algemene Ver- pleegkunde, Psigiatriese Verpleegkunde, Verloskundige Verpleegkunde en Gemeenskapsverpleegkunde aangebied kan word.

Hierdie uitdaging is nie net gerig aan die instansies wat dosente oplei nie, maar ook aan elke individuele verpleegopvoeder.

\section{BIBLIOGRAFIE}

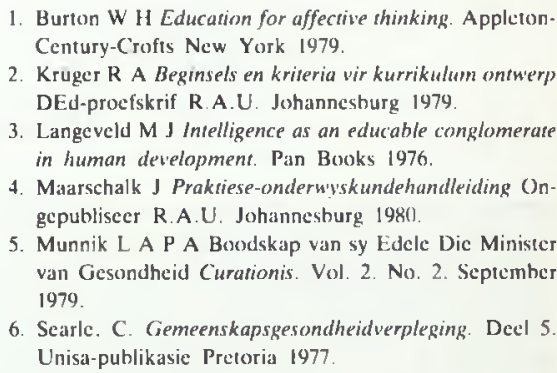

\section{COMPLETED RESEARCH VOLTOOIDE NAVORSING}

\section{DIE ROL VAN DIE VERPLEEGSTER IN DIE VERSORGING EN BEHANDELING VAN DIE KIND MET AKUTE LIMFATIESE LEUKEMIE}

\section{Johanna Elizabeth Smit \\ Magister Curationis (Gevorderde Algemene Ver- pleegkunde) \\ Departement Verpleegkunde, Universiteit van Pre- toria}

Die positiewe resultate wat tans verkry word met die behandeling van kinders met akute limfatiese leukemie het daartoe gelei dat die veranderde rol van die verpleegster in die versorging en behandeling van hierdie kinderpasiënte in oënskou geneem word.

Die navorser beskryf en lig die rol van die verpleegster uit in die verskillende fases van die behandeling naamlik die induksiefase, sentrale senuweestelselbehandeling, die instandhoudings- en herinduksiefase. Kliniese data aangaande die siekteproses, die terapie, die psigo-sosiale implikasies van die siekte en behandeling en die versorging van die sterwende kind word ook bespreek. Aandag word verder geskenk aan die onderrig en ondersteuning van die kind en sy ouers in die verskillende stadiums van die siekte.

'n Aantal aanbevelings wat kan bydra tot verbeterde pasiëntsorg word gemaak. Die navorser is verder ook van mening dat alle verpleegsters wat hierdie pasiënte versorg 'n nabasiese kursus in onkochemoterapie-verpleegkunde moet deurloop.

\section{'N ONDERSOEK NA DIE OMSET VAN VERPLEEGPERSONEEL IN TRANSVAALSE PROVINSIALE HOSPITALE 1969 - 1978 Johanna Gezina Petronella van Niekerk Magister Curationis (Verpleegadministrasie) Departement Verpleegkunde, Universiteit van Pre- toria}

Die waarnemings wat ten opsigte van die bedankingsyfer van geregistreerde verpleegkundiges uit die Transvaalse Provinsiale Hospitale gemaak is, het die navorser genoop om vas te stel wat die omvang van, asook die redes vir, die gemelde omset was.

'n Omskrywing van personeelomset is gegee en 'n norm daarvoor vasgestel. In navorsing is gevind dat die omset van geregistreerde verpleegkundiges gedurende die navorsingstydperk beduidend hoër as die vasgestelde norm was. Vervolgens is navorsing gedoen oor die waarskynlike redes vir die omset van geregistreerde verpleegkundiges. Die navorsingsresultate het geen spesifieke redes vir die omset geïdentifiseer nie. 'n Literatuurstudie is gedoen om die werklike redes vir omset te bepaal, waarin gevind is dat geen enkele faktor as sodanig aanleiding gee tot bedanking nie, maar dat daar telkens 'n groep faktore is wat ontevredenheid veroorsaak en tot uiteindelike bedanking aanleiding gee.

Aanbevelings ter oplossing van die probleem is binne die raamwerk van die personeeladministratiewe beginsels gedoen. 